\title{
Decomposition Analysis of Carbon Emissions in Jing-Jin-Ji Region of China: 2001-2012
}

\author{
Qiaozhi Zhao'; Qingyou Yan² \\ Economics and Management School, North China Electric Power University, Baoding, China
}

Zhaoqiaozhi2006@126.com,yanqingyou@163.com

Corresponding author: Qiaozhi Zhao

\begin{abstract}
Keywords: Carbon emissions, Jing-Jin-Ji region, LMDI, region coordination
Abstract: Jing-Jin-Ji region shoulders a heavy task of carbon emission mitigation. Exploring the main dominating factors is helpful to find out measures. This paper analyzes five factors which influence carbon emissions in Jing-Jin-Ji region from 2001 to 2012 based on LMDI method. Results showed that: Firstly, economic output growth is the most dominating factor to drive emission growth. Secondly, population scale, energy structure and industry structure have positive effects yet. Technological progress didn't make a significant effect in emissions. National strategy of implementing Jing-Jin-Ji integration plan in 2015 supplied opportunities for Jing-Jin-Ji region to restructure its economy and energy in the $13^{\text {th }}$ five year. Policies to stimulate technological input into energy intensity should be highlighted to reduce emissions. New energy industries development and undertaking Beijing's transfer will accelerate Jing-Jin-Ji's carbon dioxide mitigation.
\end{abstract}

\section{Introduction}

$\mathrm{CO}_{2}$ emissions and the associated greenhouse effects have triggered many global concerns. Energy consumption in China has sharply increased accompanying with rapid industrialization and urbanization (EIA 2011)[1] and has become the largest $\mathrm{CO}_{2}$ emitter (IEA, 2009[2]; MNP, 2007[3]). As a responsible country, China has made a promise that compared with that carbon emissions per GDP will be cut down by forty or fifty percent, compared with that in 2005 . As important economic circle in China, Jing-Jin-Ji's economic output accounts for ten percent in China and releases $12 \%$ of emissions during 2001-2012. Thus, it shoulders a heavy task of mitigating emissions. An investigation of dominating its emission growth is necessary to realize the low carbon transformation and sustainable development. Decomposition technique is properly fit for studying the factors' effect decomposition, exploring the key factors and identifying policies.As an index decomposition analysis method, Ang argued that LMDI was the most preferred decomposition method for the theoretical basis, zero residual, adaptability, result interpretation and other properties among decomposition methods [4]. Many researchers (Wang 2005; Guo 2010; Tu 2014; Wenwen Wang 2014; Frédéric Branger 2015) used LMDI method to explore the relative contributions quantitatively to the growth of energy consumption and carbon emissions [5-9]. This paper is trying to use LMDI to decompose Jing-Jin-Ji carbon dioxide emissions.

\section{Methodology}

\subsection{Decomposition model}

For carbon emissions decomposition analysis, Kaya firstly proposed Kaya identity [10]:

$$
C=\frac{C}{E} \cdot \frac{E}{G D P} \cdot \frac{G D P}{P} \cdot P
$$

To further analyze categorized by industry sectors and energy types, Eq.(1) is rewritten as Eq.(2):

$$
\mathrm{C}=\sum_{i, j} \frac{C_{i j}}{E_{i j}} \cdot \frac{E_{i j}}{E_{i}} \cdot \frac{E_{i}}{I_{i}} \cdot \frac{I_{i}}{G D P} \cdot \frac{G D P}{P} \cdot P=\sum_{i, j} C F_{i j} \cdot E S_{i j} \cdot E I_{i} \cdot Y S \cdot E Y \cdot P
$$

Where i,j denotes fuel types and industry sectors; $C F_{i j}$ denotes emission coefficients, $E S_{i j}$ is energy structure, $E I_{i}$ denotes energy intensity, $Y S$ denotes industrial structure, $E Y$ denotes economic 
output. $C^{0}$ and $C^{t}$ denote carbon emissions in period 0 and period t. $\Delta C^{t}$ is the quantity change from period 0 to period t. According to Ang, $\Delta C^{t}$ can be decomposed into emission coefficient effect $\left(\Delta C_{C F}^{t}\right)$, energy structure effect $\left(\Delta C_{E S}^{t}\right)$, energy intensity effect $\left(\Delta C_{E I}^{t}\right)$, economic structure effect $\left(\Delta C_{Y S}^{t}\right)$, economic output effect $\left(\Delta C_{\mathrm{EY}}^{t}\right)$ and population scale effect $\left(\Delta C_{P}^{t}\right)$.

Ang brought the LMDI formula that when $\mathrm{V}=\mathrm{V}_{\mathrm{X} 1} \cdot \mathrm{V}_{\mathrm{X} 2} \cdots \mathrm{V}_{\mathrm{X} n}, \Delta \mathrm{V}_{\text {tot }}=\Delta \mathrm{V}_{\mathrm{X} 1}+\Delta \mathrm{V}_{\mathrm{X} 2}+\cdots+\Delta \mathrm{V}_{\mathrm{X} n}$ and $\Delta \mathrm{V}_{\mathrm{Xk}}=\sum_{i} \ln \left(X_{k, i}^{T} / X_{k, i}^{0}\right) \cdot L\left(V_{i}^{T}, V_{i}^{0}\right)$. He also suggested analytical limit to handle with zero values. Thus it is obtained as Eq.(4)

$$
L(a, b)=(b-a) /(\ln b-\ln a), L(a, a)=a(a \neq 0) \text { and } L(a, b)=0(a b=0)
$$

Because there is little change in years of carbon emission coefficients of energy types and it is difficult to measure these coefficients in technology, we assume they are constant and we use IPCC report as emission coefficients. Thus in LMDI, we have $\ln \left(C F_{i t} / C F_{i 0}\right)=0$ and $\Delta C_{C F}^{t}=0$. And this paper only considers the latter five factors.

\subsection{Data sources and description}

Since China signed Kyoto Protocol in 1998 and made a 2002 target to cut down emissions per GDP by 40 or 45 percent. China made more and more efforts to emission mitigation. Under this background, this paper is trying to study its final effects during 2001-2012. In China, Jing-Jin-Ji region releases about 20 percent carbon emissions and it shoulders heavy tasks to cut down their emissions. Energy structure in this paper mainly considers coal, coke, crude oil, fuel oil, gasoline, kerosene, diesel oil and natural gas. To avoid double calculation, electricity and heat energy is excluded. Economic output is categorized from six industry sectors: i) Primary industry: farming, forestry, animal husbandry, fishery and water conservancy; ii) Industry; iii) Construction; iv)Service industry. Residential energy consumption is excluded in this paper. The energy consumption data are total final consumption quantity and from China Energy Statistical Yearbook for 2001-2012 [11-12]. They are in physical quantity, the former seven energy types units are $10^{4}$ tons $(t)$ and the natural gas unit is $10^{8} \mathrm{~m}^{3}$. Thus we will convert them into standard coal consumption in $10^{6}$ tsc (tons standard coal). The coefficients for coal, coke, crude oil, fuel oil, gasoline, diesel oil, kerosene and natural gas are 0.7143 tsc/ton, 0.9710 tsc/ton, 1.4286 tsc/ton, 1.4286 tsc/ton, 1.4714 tsc/ton, 1.4571 tsc/ton, 1.4714 tsc/ton, $13.30 \mathrm{tsc} / 10^{4} \mathrm{~m}^{3}$, respectively[12]. Economic data in Jing-Jin-Ji region such as GDP, valued added are from China Statistical Yearbook, Beijing Statistical Yearbook, Tianjin Statistical Yearbook or Hebei Economic Yearbook for the appropriate periods [14-16]. They are measured in billion yuan. Population is calculated by the average value of adjacent years. The carbon emission coefficients are from IPCC. Coefficients for raw coal, coke, crude oil, fuel oil, gasoline, diesel oil , kerosene and natural gas are $0.755910^{4} \mathrm{t} / 10^{4}$ tce, $0.855010^{4} \mathrm{t} / 10^{4}$ tce, $0.58610^{4}$ t/10 $4^{4}$ tce, $0.61910^{4} \mathrm{t} / 10^{4}$ tce, $0.55410^{4} \mathrm{t} / 10^{4}$ tce, $0.59210^{4} \mathrm{t} / 10^{4}$ tce, $0.57110^{4} \mathrm{t} / 10^{4}$ tce, $0.44810^{4}$ $\mathrm{t} / 10^{4}$ tce, respectively[13].

\section{Results and discussion}

\subsection{Overall effects analysis}

Using Eq.(2) and Eq.(3), we calculated the five effects in Jing-Jin-Ji region during 2001-2012. Results are shown in Table 1. From Table 1, we find that output is the main driving factors and energy intensity effect is the most negatively driving factors during 2001-2012 during this period. Energy intensity effect was negative every year except 2003 and 2005. Energy structure effect to carbon dioxide emissions was positive annually during 2003-2006, 2008-2012 and negative in 2001-2012, and 2007. In accumulated carbon dioxide emissions change (101.38 million tons), economic output effect contributed $132.46 \%$, energy intensity effect contributed - $47.37 \%$, population scale effect contributed $10.99 \%$, energy structure effect contributed $2.17 \%$ and industry structure effect contributed $1.77 \%$. 
Table 1: Decomposition results of carbon dioxide emissions in Jing-Jin-Ji region during 2001-2012 (unit: $10^{6}$ tons)

\begin{tabular}{ccccccc}
\hline Year & $\Delta C_{E S}^{t}$ & $\Delta C_{E S}^{t}$ & $\Delta C_{Y S}^{t}$ & $\Delta C_{\mathrm{E} Y}^{t}$ & $\Delta C_{D}^{t}$ & $\Delta C^{t}$ \\
\hline 2001 & -0.11 & -3.27 & -0.06 & 5.28 & 0.37 & 2.21 \\
2002 & 0.24 & -1.90 & -0.03 & 5.94 & 0.34 & 4.60 \\
2003 & 0.18 & 1.14 & 0.07 & 7.30 & 0.42 & 9.11 \\
2004 & 0.38 & -1.00 & 0.00 & 9.57 & 0.50 & 9.45 \\
2005 & 1.27 & 10.01 & 0.10 & 10.94 & 0.67 & 22.99 \\
2006 & 0.59 & -3.49 & 0.06 & 13.15 & 0.86 & 11.17 \\
2007 & -1.11 & -8.61 & -0.04 & 14.49 & 0.95 & 5.69 \\
2008 & 0.65 & -5.28 & 0.29 & 12.20 & 0.99 & 8.86 \\
2009 & 0.09 & -10.23 & 0.22 & 13.29 & 1.04 & 4.41 \\
2010 & 0.33 & -12.85 & 0.34 & 14.57 & 1.84 & 4.22 \\
2011 & -0.07 & -2.63 & 0.47 & 13.85 & 1.99 & 13.61 \\
2012 & -0.24 & -9.91 & 0.35 & 13.69 & 1.16 & 5.05 \\
total & 2.20 & -48.03 & 1.79 & 134.29 & 11.14 & 101.38 \\
\hline
\end{tabular}

\subsection{Decompositions effects analysis}

Economic output effects analysis. Table 1 indicates economic output growth was the most driving factor during 2001-2012, which contributed 132.46\% to carbon dioxide emissions. Although there were fluctuations in economic output effect, its driving effect was undoubtedly the most one in absolute value and ratio percent. The ratio was even $344 \%$ in 2010 . It reveals that economic development depends much on energy consumption and led to carbon dioxide emissions during economic growth. To fundamentally change this situation, a shift in the mode of economic growth mode is necessary. Under the background of Jing-Jin-Ji integration plan's implementation and the $13^{\text {th }}$ five-year plan's preparation, more concerns are put forward to green development and industrial upgrading to transform the economic development mode.

Energy intensity reflects the overall efficiency of energy and economic activity. Energy intensity made a negative effect on carbon dioxide emissions in 2001-2012. It proved that technology progress restrained carbon dioxide emissions' growth and there was no significant energy rebound effect. Hebei consumed the most share energy and emissions proportion kept rising in Jing-Ji-Ji region. Its energy intensity is more than that of Beijing and Tianjin. Thus to continuously exert energy intensity's negative effect on carbon emissions in Jing-Jin-Ji region, Hebei province is the key factor. For Hebei province, absorbing more technology spillover effect from Beijing and Tianjin is important. As regional integration was brought out as one national strategy in 2014, to ease Beijing's non capital function will bring more opportunities to decrease its energy intensity in the future.

Industrial structure change contributed accumulated contribution in 2001-2012 only $1.77 \%$, much smaller than energy intensity factor. Service industry proportion was $45 \%$ and secondary industry was $38 \%-40 \%$. Industrial structure did not take significant change, its effect cannot be released. In the integration plan, it emphasized industrial structural upgrading by dislocation development to complement each other for three regions. Tianjin will develop advanced manufacturing industry and harbor industry priorly in the future. Hebei will focus on automobile manufacturing, logistics industry and new energy industries. Beijing will develop technical research industries. All this will give more and more opportunities for three areas to upgrading their industries and improving industrial structure to reduce energy consumption level.

Accumulated effect of population scale contributed to $10.99 \%$ to total carbon dioxide emissions during 2001-2012. Fig. 9 reveals that the population scale increased annually with slightly rising growth rate. The contribution ratio was declining during 2001-2005, inclining during 2005-2010 and there was a peak point in 2010. It dropped quickly in 2011 and then rose in 2012. In Fig.2, we can conclude that there was a big drop in energy intensity and a sharp rise in economic output effect, which made the two effects ratio decreased and then population scale effect increased. There is another reason that with GDP per capita was increasing at a high speed, people's energy demand 
was accordingly rising and carbon emissions from urbanization and living consumption was increasing. For Jing-Jin-Ji region, not only population scale should also be controlled, but also it should continuously guide people living mode transformation to more energy-saving and low carbon life, i.e. green public transportation and waste treatment.

Energy structure effect was positive or negative in 2001-2012. Coal proportion decreased from $52.66 \%$ to $33.98 \%$ in $2001-2012$ and coke proportion increased from $22.83 \%$ to $42.72 \%$. Coal and coke emission coefficients $(0.7559,0.8550)$ are greater than each of other energy types and we named them high-carbon energy types. We can conclude that Jing-Jin-Ji region high carbon energy consumption did not decrease significantly and it led to its driving effect was not significant on the carbon dioxide emissions during 2001-2012. Coke energy is consumed more than $90 \%$ by industry in this region. Thus to improve regional energy consumption structure depends on the decreasing the proportion of high-carbon energy consumption in the future.

\section{Conclusions}

By applying LMDI, we consider five effects which influenced Jing-Jin-Ji region emissions. Economic output growth is the main driving factor and energy intensity is the only negative factor in 2001-2012. Under the regional integration background, economic restructure adjustment should be emphasized on that Beijing as an innovation center, Tianjin as an advanced manufacturing center and regional harbor center and Hebei as logistics, automobile, pharmaceutical production and new energy industries center. New energy industries development will improve regional energy structure to mitigate emissions and polish up environments. Secondly, more funds will be invested to relieve the dependence of high-carbon energy. North Hebei has rich wind and solar resources, and its economy is backward. Developing its new energy and renewable energy industry in that area will bring more economic development opportunities and transport clean energy to Jing-Jin-Ji region. National strategy of promoting integration brings many opportunities for the three areas in Jing-Jin-Ji region.

\section{Acknowledgements}

This work was financially supported by the Fundamental Research Funds for the Central Universities (Grant nos.9160613012).

\section{References}

[1] EIA: 'International Energy Statistics', US Energy Information Administration. 2011, Washington D.C.USA.

[2] IEA: ' $\mathrm{CO}_{2}$ emissions from fuel combustion 2008 edition', International Energy Agency, 2009, Paris, France.

[3] MNP: 'China now no. $1 \mathrm{CO}_{2}$ emissions, USA in second position.' , Netherlands Environmental Assessment Agency, 2007.

[4] Ang, B.W. and Zhang, F.Q.: 'A survey of index decomposition analysis in energy and environmental studies', Energy, 2000, 25, 1149-1176.

[5] Wang C, Chen J and Zhou J: 'Decomposition of energy-related $\mathrm{co}_{2}$ emissions in China: 1957 2000', Energy, 2005, 30(1), 73 - 83.

[6] Guo Chao-xian: 'Decomposition of China's carbon emissions: based on LMDI method', China Population, Resources and Environment, 2010, 20 (12), 4-9.

[7] Tu Hongxing, Xiaoxu and Xu Songtao: 'An analysis of carbon dioxide emissions by Chinese industries based on LMDI method', Journal of Central South University, 2014, 20 (4), 31- 36.

[8] Wenwen Wang, Xiao Liu, Ming Zhang and Xuefeng Song: 'Using a new generalized LMDI method to analyze China's energy consumption', Energy, 2014, 67, $617-622$.

[9] Frédéric Branger and Philippe Quirion: 'Reaping the carbon rent: Abatement and overallocation profits in the European cement industry, insights from an LMDI decomposition analysis', 
Energy Economics, 2015, 47, 189-205.

[10]Kaya Y. Impact of carbon dioxide emission on GNP growth: interpretation of proposed scenarios. Paris: IPCC Energy and Industry Subgroup, 1989.

[11]National Bureau of Statistics, People Republic of China. China Statistical Yearbook. Beijing, China Statistics Press, 2000-2013.

[12]Department of Energy Statistics, National Bureau of Statistics. China Energy Statistical Yearbook. Beijing, China Statistics Press, 2000-2013.

[13]2008 IPCC Guidelines for National Greenhouse Gas Inventories. IPCC, 2008.Switzerland: IPCC.

[14]Beijng Municipal Bureau of Statistics, Beijing Statistical Yearbook. Beijing, China Statistics Press, 2000-2013.

[15] Tianjin Municipal Bureau of Statistics \& Survey Office of the National Bureau of Statistics in Tianjin, Tianjin Statistical Yearbook. Beijing, China Statistics Press, 2000-2013.

[16]Hebei Provinical Bureau of Statistics. Hebei Eocnomic Yearbook, Beijing, China Statistics Press, $2000-2013$. 